\title{
A SIMPLE ELECTRONIC COMMUTATOR FOR A DC MOTOR
}

\author{
Ayman Ali ${ }^{1}$, Salama Abo Zaid ${ }^{2}$, Abdel Samie Kotb ${ }^{2}$ \\ ${ }^{1}$ Aircraft Systems Maintenance Engineer, EgyptAir, Cairo Airport, Egypt \\ ${ }^{2}$ Electric Power \& Machines, Faculty of Engineering, Al-Azhar University
}

\begin{abstract}
The commutator is the weak point of any DC motor and its wear may limit the motor life, however it is an essential part of any DC motor and the commutatorless DC motor is not a true. Many types of brushless DC motors are available now. They have a permanent magnet synchronous motor structure and are driven by special controllers. These controllers are mainly inverters which are considered as electronic commutators. With using solar energy which gives pure DC voltage, it is more suitable to use DC motors or DC drives which can be fed from this kind of energy.

In this paper we will introduce a simple electronic commutator design which is based on a single chip. The proposed controller is small enough to be integrated with the motor.
\end{abstract}

\section{INTRODUCTION}

\subsection{Electric Drive}

An electric drive is an electromechanical system that converts electrical energy to mechanical energy of the driven machine. As illustrated in Fig (1) the electric drive basically consists of motor and controller. The motor is ac, dc or special type and the controller contains power unit and control unit.

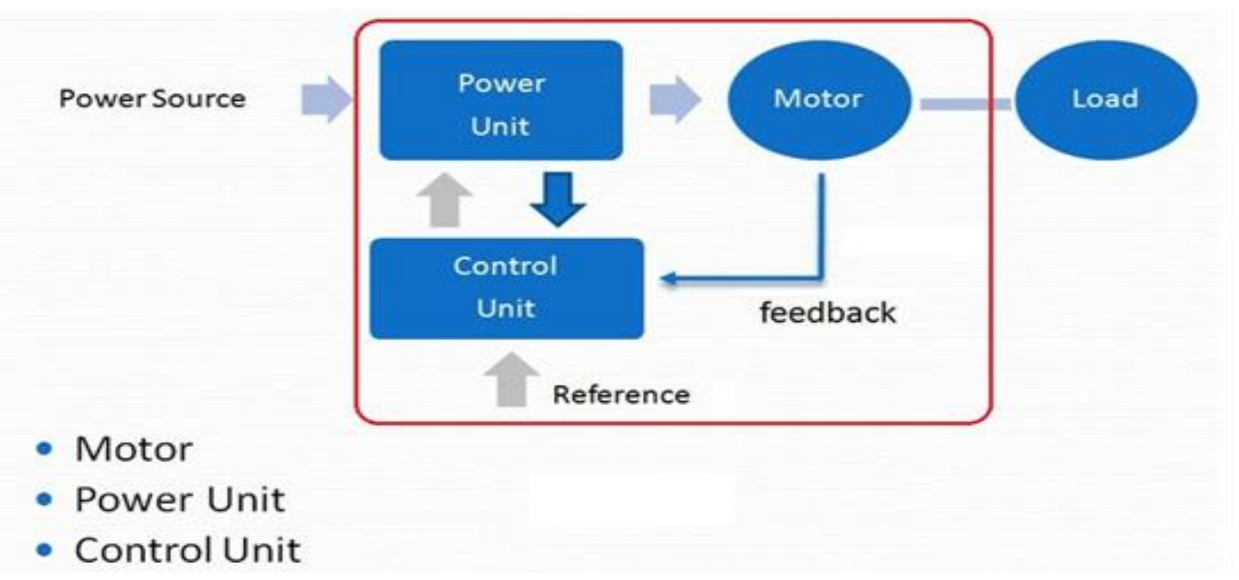

Fig (1) Electric Drive block diagram

The difference between dc motor and dc drive is the controller where both of them are worked by dc supply. Accordingly if you are able to connect the motor directly on the available dc supply, so you just need a motor and if you are not able to connect the motor to the available dc supply, so you need a dc drive.

Electric drives use approximately $70 \%$ of generated electrical energy. It is more than 100000 billions kilowatt-hours per year. It was reported that currently $75 \%$ of these operate at pump, fan, and compressor applications $97 \%$ of which work at fixed speeds, where flow is controlled by mechanical methods. Only 3 to $5 \%$ of these drives are operated at variablespeed control systems. Electric drive systems make up about one-third of overall automation equipment. The cost of the informational and electrical parts takes more than half of the 
overall drives value [4].

\subsection{Types of Electric Drives}

Electric drives can be classified based on the type of the motor being used. This may be ac or dc motor. Drives can also be classified based on types of control functions (e.g. position control drives, variable speed drives, torque control drives, etc.) however it is not common. A third classification can be based on the definition of electric drive which considers the source type or input type.

So we can define the dc drive as an electromechanical unit which converts dc power to mechanical power i.e. its input is a dc supply and its output is a mechanical rotation.

The possible forms of drive motors are:

i) dc motors fed from dc supply

ii) dc motors fed from ac supply

iii) ac motors fed from ac supply [5]

iv) ac motors fed from dc supply

We can consider (i \& ii) as dc drives and (iii \& iv) as ac drives if we classify according to motor type or consider (i \& iv) as dc drives and (ii \& iii) as ac drives if we classify according to supply type.

\subsection{Motors Classification}

Mainly dc motors are divided into brushed and brushless as follows:

Brushed motors commutate via physical contacts, often spring-loaded graphite brushes biased against the commutation bars. Brushed motors are the dc traditional motors which include series, shunt, and compound configurations

Brushless motors commutate electronically with no physical brush contacts. One common technique for positional feedback to control commutation is the use of Hall Effect sensors to detect rotor position. Commutation options include trapezoidal and sinusoidal drive signals to the motor.

Brushless dc (BLDC) motors have gained more attention and widely used in several industrial and household applications, including electric pumps and compressors, robotics, motion control systems, ventilation fans and blowers, air conditioners, and traction controls.

\section{BRUSHLESS DC MOTOR}

\subsection{General}

Brushless direct current (BLDC) motor drives are becoming more popular due to its high power efficiency, high torque to weight and inertia ratios, high power density, high dynamic response, high reliability, compact size and simple control. The BLDC motors with trapezoidal back-EMF are used extensively in medical, aviation, electric vehicles, industrial and defense motion-control applications. Electronically commutated BLDC motors are highly reliable and require less maintenance due to the elimination of high-wear parts such as standard mechanical commutator and brush assembly [1].

BLDC motor normally uses three Hall Effect sensors on the non-driving end of the motor terminals for detecting rotor positions. The motor powered by three phase six pulse inverter which is controlled based on the rotor position information for electronic commutation. The rotor position information get from the Hall sensors. Combination of output of these sensors decodes into six unique states which are used for switching of the inverter.

The BLDC motor is basically a synchronous rotating electric machine with a classical threephase concentrated stator winding whereas the rotor has permanent magnets producing a trapezoidal back EMF waveform. The operation of BLDC motors is electrically commutated and powered by a dc electric source via an integrated three-phase power inverter, which produces AC rectangular stator current waveforms to drive the motor [6]. The BLDC motor also called as synchronous motor because the magnetic field generated by stator and rotor revolve at same frequency and benefit of this arrangement is that the BLDC motor does not experience slip like that of induction motors [2-3].

Several researches are issued for brushless dc motor solar applications whether for electric vehicles [9] or other applications. Recently, brushless DC motor drive for solar photovoltaic (SPV) fed water pumping has gained a broad attention owing to its simplicity; high 
efficiency; easy-to-drive features; no maintenance requirement and compactness [7-8].

\subsection{Construction of a BLDC}

Figure 2 is a simplified illustration of BLDC motor construction. A brushless motor is constructed with a permanent magnet rotor and wire wound stator poles same a permanent magnet synchronous motor.

Electrical energy is converted to mechanical energy by the magnetic attractive forces between the permanent magnet rotor and a rotating magnetic field induced in the wound stator poles.
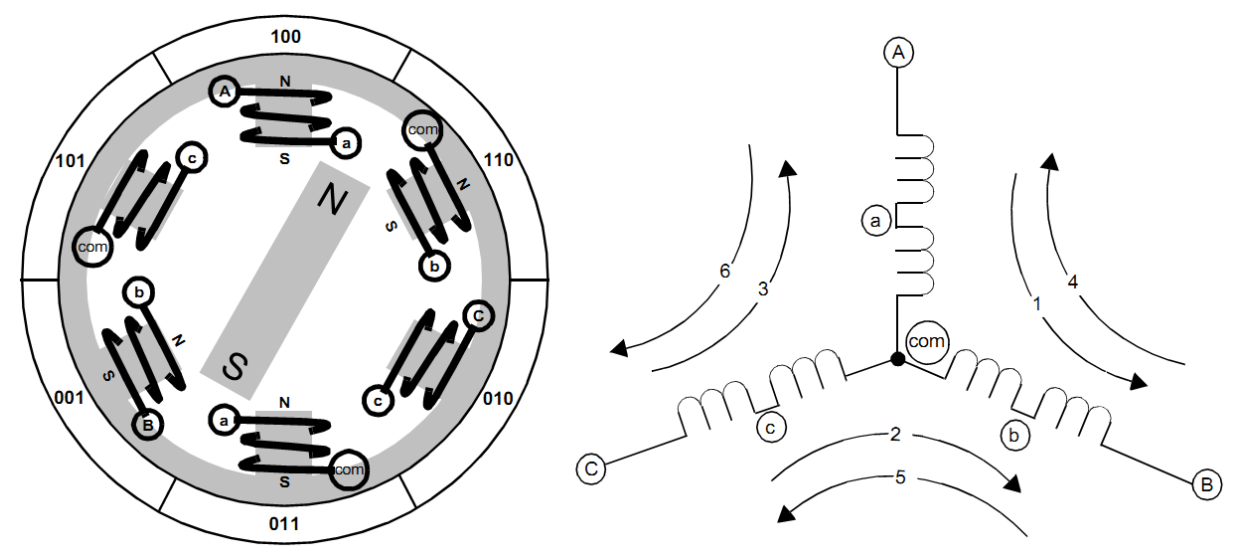

Fig. (2) BLDC motor construction

In this example there are three electromagnetic circuits connected at a common point. Each electromagnetic circuit is split in the center, thereby permitting the permanent magnet rotor to move in the middle of the induced magnetic field. Most BLDC motors have a three-phase winding topology with star connection. A motor with this topology is driven by energizing two phases at a time.

The key to BLDC commutation is to sense the rotor position, then energize the phases that will produce the most amount of torque. Commutating the electrical connections through the six possible combinations, numbered 1 through 6 , at precisely the right moments will pull the rotor through one electrical revolution.

The easiest way to know the correct moment to commutate the winding currents is by means of a position sensor. Many BLDC motor manufacturers supply motors with a three-element Hall Effect position sensor. Each sensor element outputs a digital high level for 180 electrical degrees of electrical rotation, and a low level for the other 180 electrical degrees. The three sensors are offset from each other by 60 electrical degrees so that each sensor output is in alignment with one of the electromagnetic circuits. A timing diagram showing the relationship between the sensor outputs and the required motor drive voltages is shown in Figure 3.

The numbers at the top of Figure 3 correspond to the current phases shown in Figure 2. It is apparent from Figure 3 that the three sensor outputs overlap in such a way as to create six unique three-bit codes corresponding to each of the drive phases. The numbers shown around the peripheral of the motor diagram in Figure 2 represent the sensor position code. The north pole of the rotor points to the code that is output at that rotor position. The numbers are the sensor logic levels where the Most Significant bit is sensor C and the Least Significant bit is sensor A.

Each drive phase consists of one motor terminal driven high, one motor terminal driven low, and one motor terminal left floating [10]. 


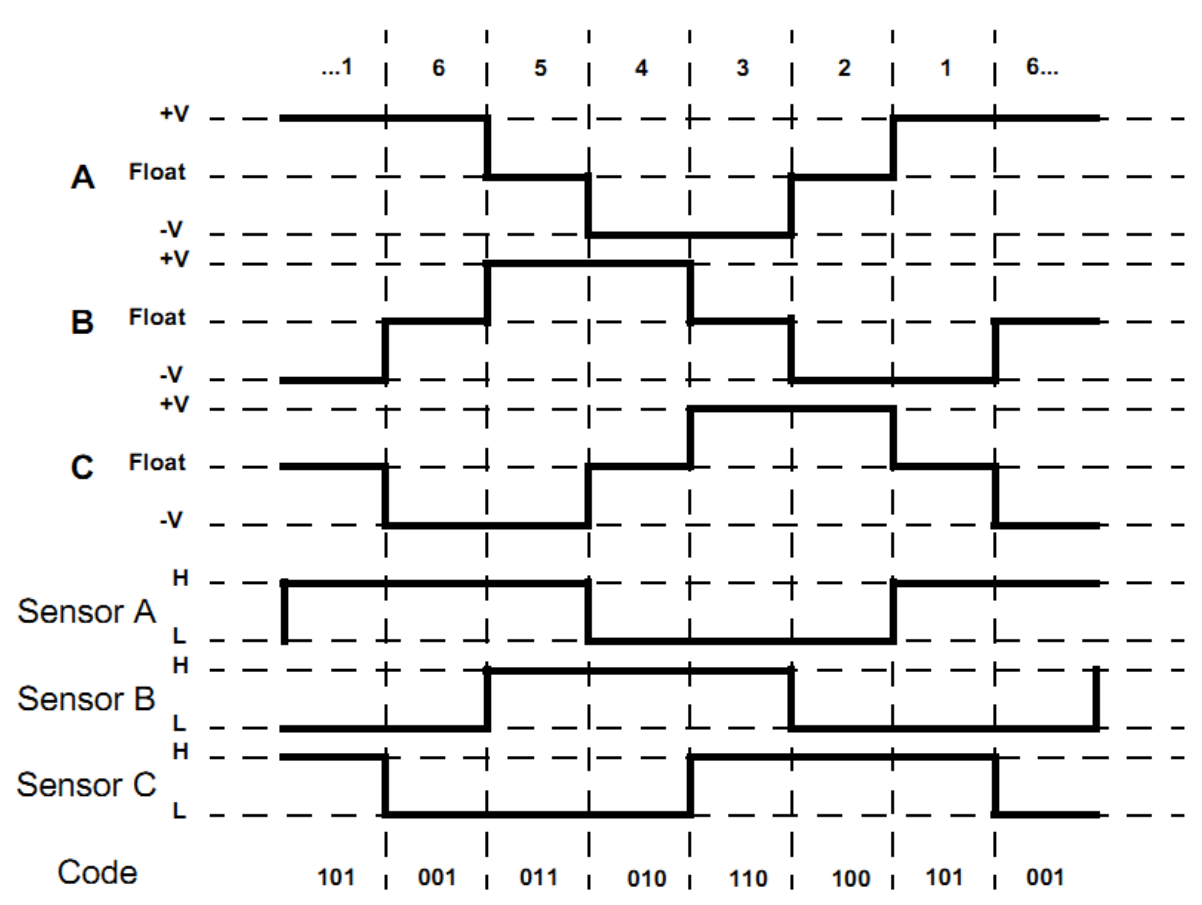

Fig. (3) BLDC motor timing diagram

\section{SIMPLE ELECTRONIC COMMUTATOR}

\subsection{Practical Electronic Commutator Circuit}

Basically the electronic commutator circuit is consists of two parts control unit and power unit. The power unit or power module is simply a six MOFETs or IGBTs three phase power module which is illustrated in Fig. (4). The control module of the electronic commutator is based on a single chip MC33035 which cover all requirements needed for our application. Chip MC33035 pin assignment is illustrated in Fig (5).

The circuit depends on $48 \mathrm{~V}$ dc supply which is generated from solar energy and will supply the power and control circuits. The electronic commutator control circuit is supplied by only $12 \mathrm{~V}$ dc. If the system is equipped by cascaded storage batteries, this voltage can be obtained from one battery or by using a step down regulator circuit.

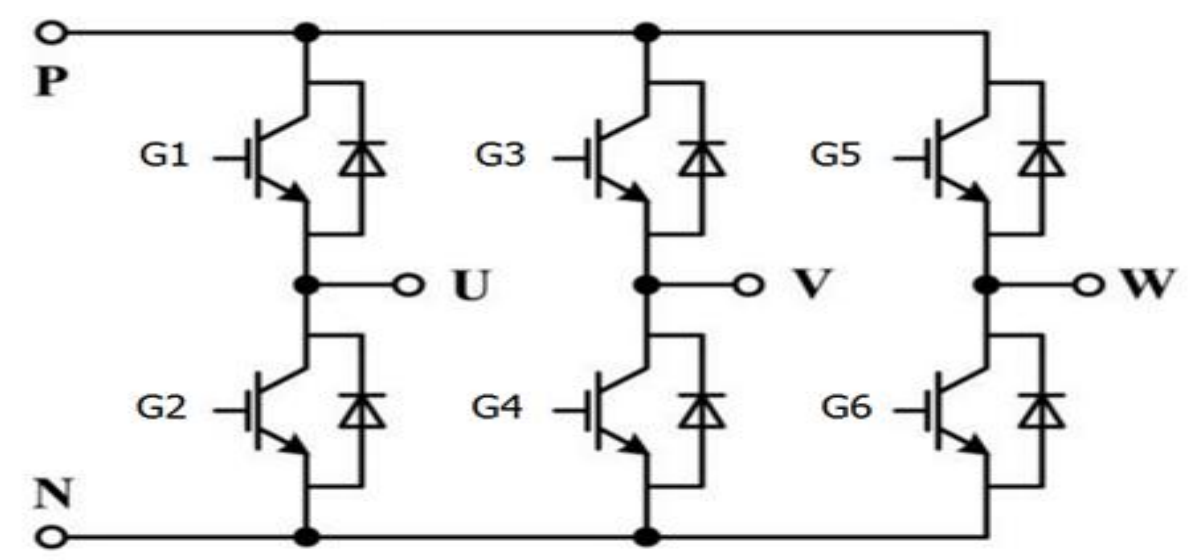

Fig (4) IGBTs Power Module 


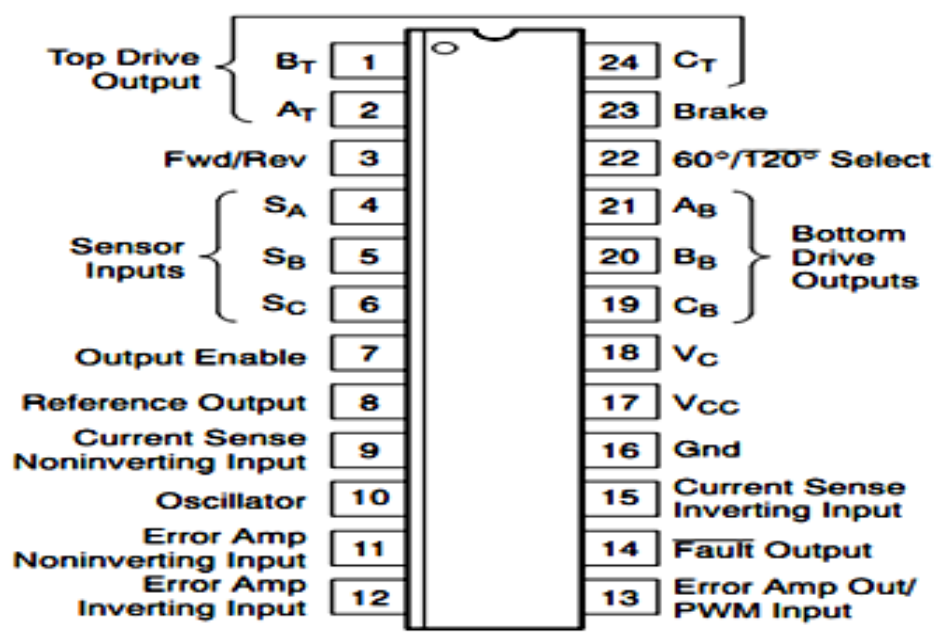

Fig (5) MC33035 pin assignment

Since gate control signals are applied with respect to the emitter terminals of the switches, the gate voltages of all the upper switches must be floating with respect to the dc bus line potentials. This calls for isolation between the gate control signals of upper switches and between upper and lower switches. The isolation provided between upper and lower switches must withstand a peak voltage stress equal to dc bus voltage.

Fig (6) illustrates the electronic commutator control module core which is implemented by the MC33035 chip. In addition to main function (electronic commutator) the IC MC33035 introduces some auxiliary functions:

Enable signal, Reverse rotation, Brake capability, Fault indication and speed variation

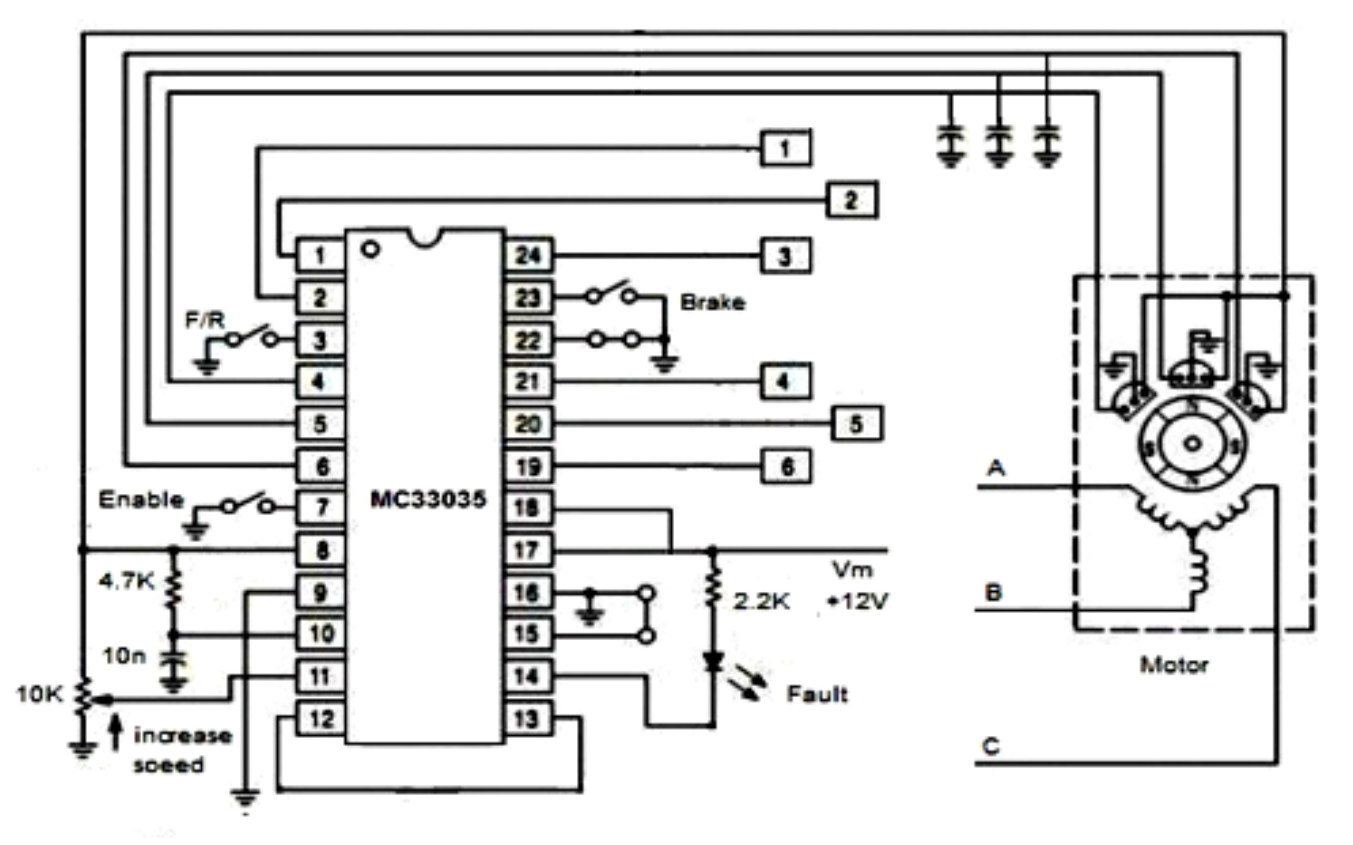

Fig (6) Electronic Commutator Control Circuit 


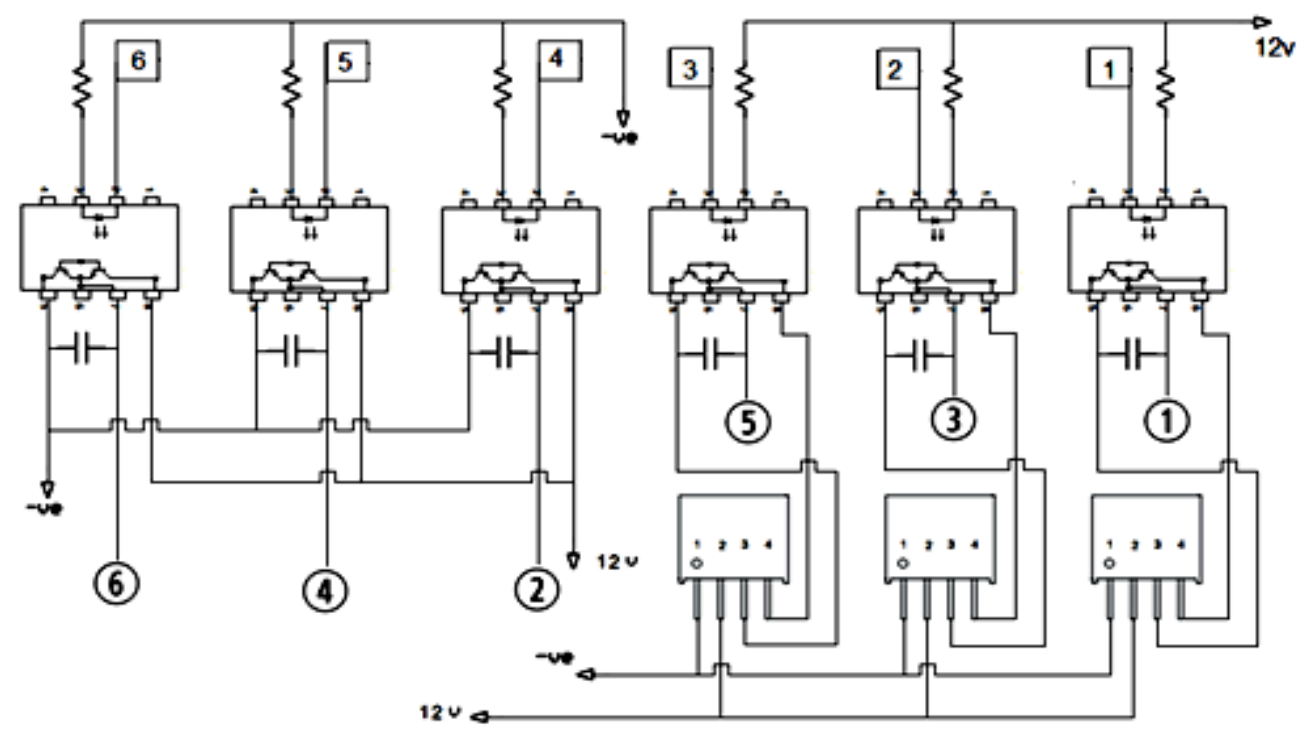

Fig (7) isolator/driver basic circuit

The circuit depends on three position encoders which are attached to the motor which identify the rotor poles position relative to stator windings. Based on this information the electronic commutator decides the necessary action. The output of the circuit is six timing signals which identify which switch should on and when. These signals will pass through isolation/ driver circuit illustrated in Fig (7) which is consisted of six opto-isolators ICs TLP250 and three ground isolator ICs B1212S-1W. Each photo coupler or opto-isolator will transfer one gate signal and drive one IGBT switch.
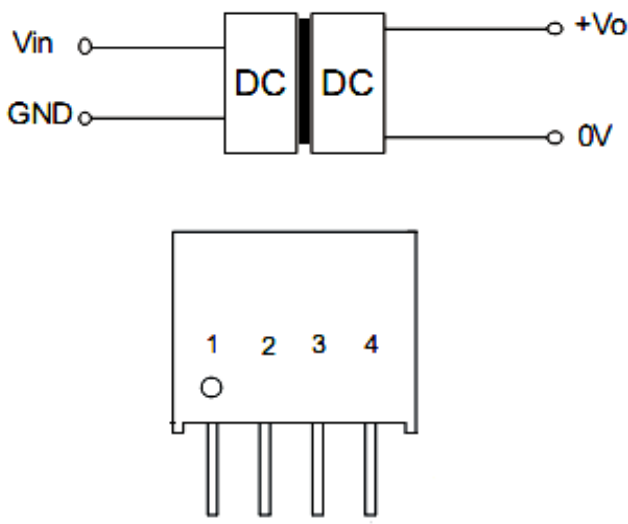

\begin{tabular}{|c|c|}
\hline \multicolumn{2}{|c|}{ FOOTPRINT DETAILS } \\
\hline Pin & B_S - 1W \\
\hline 1 & GND \\
\hline 2 & Vin \\
\hline 3 & OV \\
\hline 4 & + Vo \\
\hline
\end{tabular}

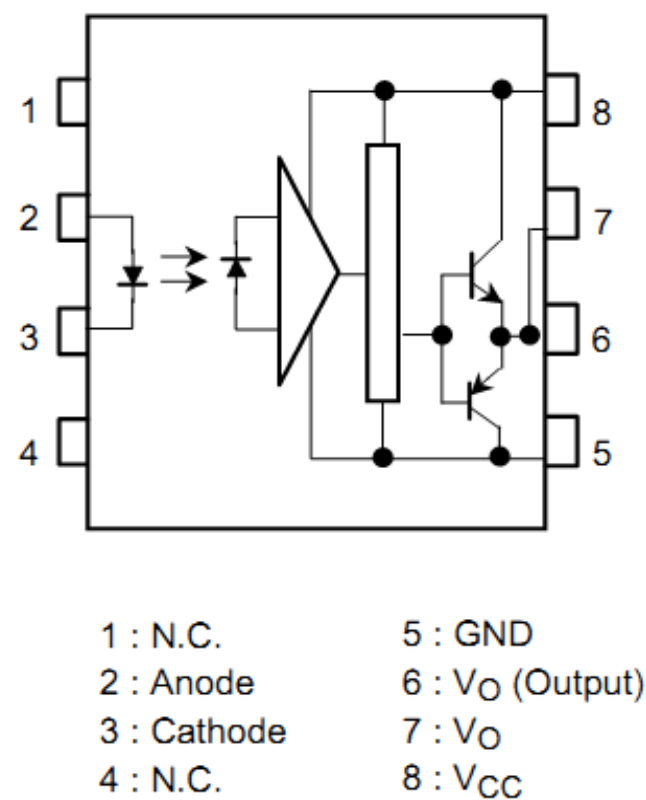

Fig (8) B1212S-1W \& TLP250 pin assignment

\subsection{Floating Power Supplies/ Ground Isolation}

It is to be remembered that the two switches of an inverter-leg are controlled in a complementary manner. When the upper switch of any leg is 'on', the corresponding lower switch should remain 'off' and vice-versa. When a switch is 'on' its emitter and collector terminals are virtually shorted. Thus with upper switch 'on', the emitter of the upper switch is at positive dc bus potential. Similarly with lower switch 'on', the emitter of upper switch of that leg is virtually at the negative dc bus potential. Emitters of all the lower switches are 
solidly connected to the negative line of the dc bus.

Since gate control signals are applied with respect to the emitter terminals of the switches, the gate voltages of all the upper switches must be floating with respect to the dc bus line potentials. This calls for isolation between the gate control signals of upper switches and between upper and lower switches. Only the emitters of lower switches of all the legs are at the same potential (since all of them are solidly connected to the negative dc bus) and hence the gate control signals of lower switches need not be isolated among themselves. As should be clear from the above discussion, the isolation provided between upper and lower switches must withstand a peak voltage stress equal to dc bus voltage. Gate-signal isolation for inverter switches is generally achieved by means of optical-isolator (opto-isolator) circuits.

The circuit on the output side is connected to a floating dc power supply. The control circuit supply ground is isolated from the floating-supply ground of the output. This configuration necessitates four control power supplies, one supply for control circuit in addition to all the lower IGBTs and three individual supplies for the upper IGBTs with proper isolation circuit. Supply voltage of each pre driver is usually in the range of $10 \mathrm{~V}$ to $20 \mathrm{~V}$.

In motor control or inverter systems, a full-bridge topology, Fig (4), that comprises six insulated-gate bipolar transistors (IGBTs) requires several isolated power supplies or dc-to-dc converters for the IGBT gate drives. For example, it is common to use three isolated power supplies for each of the three top-bridge IGBTs and one isolated power supply for the bottombridge IGBTs. These transformer-based power supplies take up a significant amount of printed circuit board (PCB) space and require layout design considerations.

In our project we used three dc/dc converter/ isolator of IC B1212S-1W to get a three floating power supplies for the three upper IGBTs in the power module to isolate the IGBTs gate grounds and avoid short circuit during operation.

When these signals are transferred to IGBTs gates of switches (G1, G2, .. G6) of Fig (4) it will convert the dc input power into AC power on terminals $\mathrm{U}, \mathrm{V}, \mathrm{W}$ in order to change stator poles according to rotor poles position for continuous torque production.

\section{CONCLUSIONS}

- The inverter is not a mandatory and can be omitted from system if we use a direct dc power and the DC loads are available.

- The conventional dc motors problems can be avoided by using brushless type as in the brushless dc motors there are no commutator or brushes.

- A practical electronic commutator circuit is implemented. The controller is small enough to be integrated with a brushless dc motor as a simple and reliable dc drive.

- To avoid the floating power supplies problem a new dc/dc converter IC are used for ground isolation.

\section{REFERENCES}

[1] Viswanathan V, "Commutation Torque Ripple Reduction in BLDC Motor Using Modified SEPIC converter and Three-level NPC inverter" IEEE Transactions on Power Electronics Volume: PP, Issue: 99, February 2017, DOI: 10.1109/TPEL.2017.2671400.

[2] Naman Hariom Agarwal; B. B. Pimple "Solar Photovoltaic Array based Brushless DC Motor for Fans in Indian Railways Using Maximum Power Point Tracking Algorithm" IEEE Transactions on 2015 39th National Systems Conference (NSC),DOI: 10.1109/NATSYS.2015.7489122.

[3] M. Archana; J. Anitha Thulasi; M. Belsam Jeba Ananth "An Efficient Solar Power Based Four Quadrant Operation of BLDC Motor" 2016 International Conference on Electrical, Electronics, and Optimization Techniques (ICEEOT), DOI: 10.1109/ICEEOT.2016.7755640

[4] Valery Vodovozov "Electric Drive Systems and Operation" (C) 2012 Valery Vodovozov \& Ventus Publishing ApS, ISBN 978-87-403-0166-3.

[5] Subrahmanyam, V., Electric Drives Concepts and Applications, 2nd edition. Tata McGraw-Hill Education Private Limited, New Delhi, 2011.

[6] Sarayut Amornwongpeeti, Sangkla Kreuawan "A Study of Dynamic Torque Ripples Using an Integrated Simulation Model of Brushless DC Motor and Drive Systems" 2015 18th International Conference on Electrical Machines and Systems (ICEMS), Oct. 2015, Pattaya City, Thailand. 
[7] Rajan Kumar, Bhim Singh "Solar PV-Battery based Hybrid Water Pumping System using BLDC Motor Drive" 2016 IEEE 1st International Conference on Power Electronics, Intelligent Control and Energy Systems (ICPEICES), DOI: 10.1109/ICPEICES.2016.7853662.

[8] Rajan Kumar, Bhim Singh "Single Stage Solar PV Fed Brushless DC Motor Driven Water Pump" IEEE Journal of Emerging and Selected Topics in Power Electronics, 2017, Volume: PP, Issue: 99, DOI: 10.1109/JESTPE.2017.2699918.

[9] Manivannan S; Kaleeswaran E "Solar powered electric vehicle" 2016 First International Conference on Sustainable Green Buildings and Communities (SGBC), DOI: 10.1109/SGBC.2016.7936074.

[10] Ward Brown " Brushless DC Motor Control Made Easy" Application Note AN857, 2002, Microchip Technology Inc., DS00857A. 